\title{
A Centralized Program with Stepped Support Increases Adherence to Colorectal Cancer Screening Over 9 Years: a Randomized Trial
}

\author{
Beverly B. Green, MD, MPH' ${ }^{1,2,3}$ (D), Melissa L. Anderson, MS², Andrea J. Cook, PhD ${ }^{2,4}$, \\ Jessica Chubak, $P h D, M B H L^{2,4}$, Sharon Fuller, $B A^{2}$, Richard T. Meenan, $P h D^{5}$, and \\ Sally W. Vernon, $P h D^{6}$
}

${ }^{1}$ Kaiser Permanente Washington, Seattle, WA, USA; ${ }^{2}$ Kaiser Permanente Washington Health Research Institute, Seattle, WA, USA; ${ }^{3}$ University of Washington School of Medicine, Seattle, WA, USA; ${ }^{4}$ University of Washington School of Public Health, Seattle, WA, USA; ${ }^{5}$ Center for Health Research, Kaiser Permanente Northwest, Portland, OR, USA; 'University of Texas School of Public Health, Houston, TX, USA.

\begin{abstract}
BACKGROUND: Screening over many years is required to optimize colorectal cancer (CRC) outcomes.

OBJECTIVE: To evaluate the effect of a CRC screening intervention on adherence to CRC screening over 9 years. DESIGN: Randomized trial.

SETTING: Integrated health care system in Washington state.

PARTICIPANTS: Between August 2008 and November 2009, 4653 adults in a Washington state integrated health care system aged 50-74 due for CRC screening were randomized to usual care (UC; $N=1163$ ) or UC plus study interventions (interventions: $\mathrm{N}=3490$ ).

INTERVENTIONS: Years 1 and 2: (arm 1) UC or this plus study interventions; (arm 2) mailed fecal tests or information on scheduling colonoscopy; (arm 3) mailings plus brief telephone assistance; or (arm 4) mailings and assistance plus nurse navigation. In year 3, stepped-intensity participants (arms 2, 3, and 4 combined) still eligible for screening were randomized to either stopped or continued interventions in years 3 and 5-9.
\end{abstract}

MAIN MEASURES: Time in adherence to CRC testing over 9 years (covered time, primary outcome), and percent with no CRC testing in participants assigned to any intervention compared to UC only. Poisson regression models estimated incidence rate ratios for covered time, adjusting for patient characteristics and accounting for variable follow-up time.

KEY RESULTS: Compared to UC, intervention participants had 21\% more covered time over 9 years $(57.5 \%$ vs. $69.1 \%$; adjusted incidence rate ratio 1.21 , 95\% confidence interval $1.16-1.25, P<0.001)$. Fecal testing accounted for almost all additional covered time among intervention patients. Compared to $\mathrm{UC}$, intervention

Previous Presentation

1. The Systems of Support to Increase Colorectal Cancer Screening Trial (SOS). 9-year Adherence and Outcomes. Oral presentation, International Cancer Screening Network Conference, Rotterdam, Netherlands, June 3, 2019

2. The Systems of Support to Increase Colorectal Cancer Screening Trial (SOS). 9-year Adherence and Outcomes. Oral presentation. World Endoscopy Meeting, San Diego, California, May 17, 2019

Received January 15, 2021

Accepted May 6, 2021

Published online May 28, 2021 participants were also more likely to have completed at least one CRC screening test over 9 years or until censorship (88.6\% vs. $80.6 \%, P<0.001)$.

CONCLUSIONS: An outreach program that included mailed fecal tests and phone follow-up led to increased adherence to $\mathrm{CRC}$ testing and fewer age-eligible individuals without any CRC testing over 9 years.

TRIAL REGISTRATION: Systems of Support (SOS) to Increase Colon Cancer Screening and Follow-up (SOS), NCT00697047, clinicaltrials.gov/ct2/show / NCT00697047

KEY WORDS: colorectal cancer; screening; mailed fecal tests; randomized trial; health care system.

J Gen Intern Med 37(5):1073-80

DOI: $10.1007 / \mathrm{s} 11606-021-06922-2$

(c) Society of General Internal Medicine 2021

\section{BACKGROUND}

Despite the potential of colorectal cancer (CRC) screening to reduce $\mathrm{CRC}$ mortality, CRC remains the second-leading cause of US cancer deaths. In 2021, an estimated 150,000 adults will be diagnosed with CRC, with 53,000 deaths. ${ }^{1,2}$

Randomized controlled trials ${ }^{3-8}$ and two meta-analyses provide conclusive evidence that directly mailing fecal tests to patients increases one-time $\mathrm{CRC}$ screening completion rates by $22-28 \%{ }^{9,10}$ Few trials have tested whether an ongoing mailed program improves screening adherence over time, with the longest trials lasting only 3 years. ${ }^{11-13}$ Studies on longerterm adherence to organized mailed fecal testing programs lack comparison groups. ${ }^{14-20}$

We report the 9-year results of Systems of Support to Increase Colorectal Cancer Screening and Follow-Up (SOS, R01CA121125), which randomized age-eligible patients due for CRC screening to usual care (UC) or mailed fecal tests, with some patients randomized to mailed fecal tests and stepped-intensity interventions (reminder calls, or reminder calls plus navigation). In years 3-9, patients randomized to UC continued to receive this only, whereas mailed plus 
stepped intervention patients who were still due for screening were re-randomized to continued or stopped interventions. Our a priori hypothesis was that compared to UC only, exposure to any SOS intervention would increase time in adherence with CRC screening guidelines up to 9 years after randomization. Secondarily, we assessed intervention effects on the percent of individuals with no CRC tests.

\section{METHODS}

Data were collected from August 2008 to December 2019. ${ }^{21}$ The Kaiser Permanente Washington (KPWA) Institutional Review Board approved procedures. Methods, recruitment, and results of the parent 2-year study are published. $6,22,23$

\section{Enrollment}

The setting was 21 primary care centers of KPWA, a Washington state integrated health system. Initial recruitment letters were mailed to 15,451 patients aged 50-74 who were due for CRC screening (no colonoscopy within the past 9 years, no flexible sigmoidoscopy within 4 years, and no fecal test within 9 months) based on electronic health record (EHR) and claims data. Individuals with EHR evidence of prior CRC, inflammatory bowel disease, or life-limiting illnesses (e.g., dementia) were excluded. Mailings were followed by a call to confirm eligibility and willingness to participate.

\section{Randomization}

Those verbally agreeing were enrolled (waiver of written consent) and randomized to UC only or UC plus mailed and stepped-intensity interventions for up to 9 years (Fig. 1). Year 1 randomization was stratified by clinic, age (50-64, 65-74 years), and self-reported prior CRC testing. A study database randomized enrolled individuals within each stratum using a permuted block design with randomization concealed. Due to the nature of the intervention, participants could not be blinded.

\section{Usual Care}

KPWA usual care included clinic-based strategies to promote CRC screening including an annual physician-signed letter and information on overdue tests including CRC screening. Beginning in 2010, KPWA primary care medical centers were certified as Patient-Centered Medical Homes. Activities included medical assistants determining at the time of clinic visits if patients were due for CRC screening and providing a fecal test or provider colonoscopy discussion. Outreach included reminder calls about needed care and potentially mailing patients fecal tests. Activity completeness, including reminder calls and mailing fecal tests, varied by clinic and medical assistant/physician teams. ${ }^{24}$

In 2011, KPWA and SOS switched from a high-sensitivity 3-sample guaiac kit (Hemoccult SENSA®, Beckman Coulter) to a 1-sample fecal immunochemical test (FIT) (OC-auto®), Polymedco).

\section{Interventions}

Years 1 and 2. The least intensive intervention arm 2 (mailed) received mailed fecal tests with postage paid envelopes and a number to call if colonoscopy or flexible sigmoidoscopy was preferred. Arm 3 (assisted) received mailings plus, for those still unscreened, brief phone assistance from a medical assistant to complete their CRC screening test choice. Arm 4 (navigated) received mailed and assisted interventions plus, for those still unscreened, nurse navigator support for overcoming screening barriers. Year 1-2 outcomes and comparative cost-effectiveness have been published. ${ }^{6,25}$

Years 3 and 5. Participants originally randomized to arms 2, 3, or 4 who were still enrolled and still CRC-screening-eligible were re-randomized in year 3 to continued or stopped mailed interventions. ${ }^{26}$ Randomization was stratified by prior randomization arm, clinic, and fecal test completion in year 1 or 2 (yes/no). In years 3 and 5, continued-arm participants received interventions identical to the year 1 and 2 mailed-only interventions with no brief phone assistance or nurse navigation. Stopped-arm patients no longer received study interventions. Year 3 and 5 study results are published. ${ }^{26,27}$ Year 4 had no interventions because of a funding gap.

Years 6-9. Nurse navigation was added to the continued mailed intervention in years 6-9; support followed the arm 4 intervention from years 1-2. However, support also emphasized barriers identified in year 5 qualitative assessments of reasons for non- or intermittent CRC screening completion after receipt of at least 3 mailed fecal tests. ${ }^{28}$ For example, the navigator might suggest leaving the FIT kit on the bathroom counter for a patient who kept forgetting, or might send disposable gloves to a patient concerned about handling stool. The nurse told patients they would call back in 1 month if the FIT was not completed. The nurse also assisted with steps for colonoscopy completion, if preferred by the patient (e.g., referral, appointment, preparation, transportation).

\section{Measures and Outcomes}

Baseline data were from EHRs (e.g., age, sex, comorbidity) and patient self-report at the baseline eligibility call (e.g., race, ethnicity, education). CRC testing before randomization was collected using EHR data and self-report of a prior fecal test, flexible sigmoidoscopy, or colonoscopy.

The primary outcome was the proportion of follow-up time in adherence with CRC screening guidelines (covered time) during 9 years of follow-up. ${ }^{29,30}$ Primary outcome data including colonoscopy, flexible sigmoidoscopy, and fecal test completion were collected from EHR and claims data. 


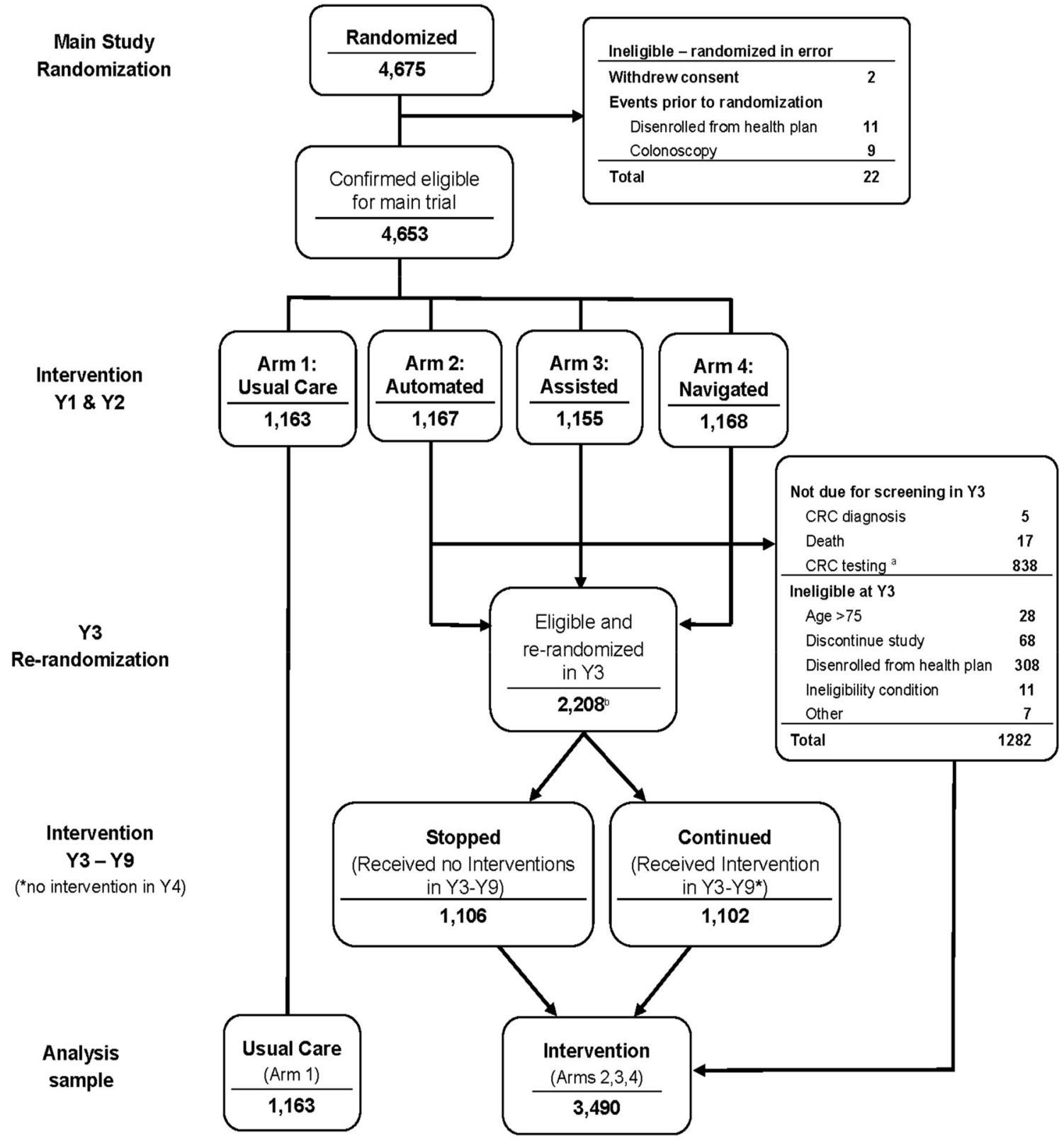

Figure 1 Systems of support to increase colorectal cancer screening and follow-up flow diagram for years 1 to 9 . *Individuals with a prior colonoscopy or who had a flexible sigmoidoscopy with an adenoma removed or a positive fecal test were not eligible for year 3 randomization. ${ }^{\dagger}$ Ineligibility condition; detected after randomization (e.g., dementia). ${ }^{*}$ Other; randomized in error (i.e., colonoscopy within 9 years of initial randomization). ${ }^{\S}$ Randomization to stopped or continued in year 3 occurred on the date the participant was due for their third round of annual screening. Intervention group participants did not receive study interventions in year 4. CRC, colorectal cancer; y, year.

Participants randomized to UC (arm 1) were compared to those initially randomized to any intervention ( $\operatorname{arms} 2,3$, and 4 combined) regardless of randomization in year 3 to stopped or continued interventions for years 3-9 (Supplementary Material, Protocol). Follow-up time was total number of days from randomization to the end of 9 years, or until a censoring event. Censoring occurred at disenrollment, study withdrawal, death, age 76, or CRC diagnosis. Consistent with KPWA screening guidelines, the number of days in adherence was calculated as 1 year, 5 years, and 10 years of screening coverage credit from completion date for, respectively, a fecal test, flexible sigmoidoscopy, or colonoscopy, until the end of study follow- up. If coverage periods from repeated testing overlapped, coverage during the overlap period was attributed to the earlier test.

A study investigator who was blinded to randomization group manually abstracted colonoscopy outcomes from the EHR, including recording if a biopsy was done at the time of endoscopy and, if so, the lesion size and pathology, focusing on adenomas and dysplasia. Adenomas were considered advanced if $\geq 1 \mathrm{~cm}$ on colonoscopy or sigmoidoscopy, or they had villous features or severe dysplasia, or if 3 or more smaller adenomas were removed. CRC was identified using diagnosis codes and a linkage with the local Surveillance, 
Epidemiology, and End Results tumor registry. ${ }^{31}$ Patients were classified as having late-stage cancer if diagnosed with American Joint Committee on Cancer IIIB or higher, or stage IIIA or lower but with evidence on chart review of metastasis or death from CRC. Information on death from CRC was from chart review.

\section{Analysis}

Comparisons between UC versus any SOS intervention group followed a modified intent-to-treat approach, with analyses including all participants except for those withdrawing consent $(n=2)$ or randomized in error $(n=20)$. We used Poisson regression to estimate the primary outcome of covered time, with number of covered days as the dependent variable and number of follow-up days as the offset parameter. The offset parameter allowed estimation of the adherence rate (proportion of observed time adherent) for censored data where participants had varying lengths of follow-up time. A binary indicator of intervention group (UC vs. any intervention) was included in the model to estimate treatment effects. Models were adjusted for age, sex, race, and education.

Whether a participant received any CRC test over 9 years was a secondary outcome. Poisson regression was used with a binary indicator for any testing as the dependent variable and number of follow-up days as the offset parameter with models adjusted for the same covariates as the covered time analysis. Interaction terms between randomization group (UC vs. intervention) and baseline age (50-64 vs. 65-74 years), sex, education, race/ethnicity (white, non-Hispanic vs. non-White or Hispanic), and CRC screening prior to SOS enrollment were added to test for differences in intervention effects on the primary outcomes by these subgroups. Each interaction was evaluated in a separate model.

Exploratory analyses were conducted to better understand testing patterns during the 9 years of follow-up. For each study year, we defined two annual measures of adherence: percent covered time in the past year and cumulative percent covered time since initial randomization. Both measures were partitioned into covered time due to fecal testing, flexible sigmoidoscopy, and colonoscopy, with mean percent covered time plotted by year. Additional exploratory analysis examined testing completed during each study year among those still needing screening. This differed from covered-time analyses by assessing new testing (i.e., no credit for testing in prior years) among the subset of the population still needing screening and not censored. Poisson models with binary testing indicators as the dependent variable and days of follow-up in the study year as the offset parameter assessed the significance of intervention effects on annual testing.

In descriptive analyses, we summarized screening outcomes by classifying each participant to the most advanced diagnosis during the study as: CRC death or metastatic CRC, non-metastatic CRC, advanced adenoma, non-advanced adenoma, colonoscopy or sigmoidoscopy without adenomas, positive fecal test with no colonoscopy follow-up, fecal test not positive, and no screening during study participation. For these outcomes, participants were censored at death from other causes, disenrollment, or opting out of participation (age $>75$ years was not censored).

\section{RESULTS}

The analytic sample comprised 4653 participants (UC only $=$ 1163, Interventions $=3490$ ) contributing CRC testing data (Fig. 1) with $2133 / 4653(45.8 \%)$ contributing 9 years of complete data. Intervention and UC groups were not different in the percent with censoring events $(54.1 \%$ and $54.2 \%$, respectively) or average length of follow-up (6.5 years). Groups were similar in age, sex, race/ethnicity, self-rated

Table 1 Baseline Characteristics and Follow-up Duration by Randomization Group. Missing Data: Race/Ethnicity ( $n=27)$; General Health Status $(n=6)$; Marital Status $(n=7)$; Education $(n=4)$; Family History $(n=72)$

\begin{tabular}{|c|c|c|}
\hline & \multirow{3}{*}{$\begin{array}{l}\begin{array}{l}\text { Usual } \\
\text { care }^{\dagger}\end{array} \\
\mathrm{N}=1163 \\
\mathrm{n}(\%)\end{array}$} & \multirow{3}{*}{$\begin{array}{l}\text { Intervention } \\
\mathrm{N}=3490 \\
\mathrm{n}(\%)\end{array}$} \\
\hline & & \\
\hline & & \\
\hline \multicolumn{3}{|l|}{ Age at baseline (years) } \\
\hline $50-64$ & $989(85.0)$ & $2977(85.3)$ \\
\hline $65-74$ & $174(15.0)$ & $513(14.7)$ \\
\hline Female & $652(56.1)$ & $1887(54.1)$ \\
\hline \multicolumn{3}{|l|}{ Race/ethnicity } \\
\hline Hispanic & $43(3.7)$ & $110(3.2)$ \\
\hline Non-Hispanic & & \\
\hline Black & $44(3.8)$ & $184(5.3)$ \\
\hline Asian & $64(5.6)$ & $173(5.0)$ \\
\hline White & $948(82.3)$ & $2780(80.0)$ \\
\hline Other & $53(4.6)$ & $227(6.5)$ \\
\hline \multicolumn{3}{|l|}{ General health } \\
\hline Excellent/very good & $720(62.0)$ & $2208(63.3)$ \\
\hline Good & $337(29.0)$ & $1050(30.1)$ \\
\hline Fair/poor & $104(9.0)$ & $228(6.5)$ \\
\hline Married or living with a partner & $835(72.0)$ & $2595(74.4)$ \\
\hline Highest education & & \\
\hline $\begin{array}{l}\text { High school graduate or equivalent, or } \\
\text { less }\end{array}$ & $190(16.4)$ & $508(14.6)$ \\
\hline $\begin{array}{l}\text { Some college, 2-year degree, or voca- } \\
\text { tional training }\end{array}$ & $368(31.7)$ & $1097(31.5)$ \\
\hline Bachelor's degree or higher & $603(51.9)$ & $1883(54.0)$ \\
\hline \multicolumn{3}{|l|}{ Primary health insurance } \\
\hline Medicaid/Basic Health & $19(1.6)$ & $31(0.9)$ \\
\hline Commercial & $907(78.0)$ & $2816(80.7)$ \\
\hline Medicare & $146(12.6)$ & $365(10.5)$ \\
\hline Private pay & $91(7.8)$ & $278(8.0)$ \\
\hline Never been screened for CRC & $537(46.2)$ & $1620(46.4)$ \\
\hline First degree relative with CRC & $55(4.8)$ & $158(4.6)$ \\
\hline Follow-up duration (days), mean (sd) & $\begin{array}{l}2384 \\
(1075)\end{array}$ & $2375(1084)$ \\
\hline Follow-up duration (years), mean (sd) & $6.5(3.0)$ & $6.5(3.0)$ \\
\hline $\begin{array}{l}\text { Censored during 9-year follow-up, } \mathrm{n} \\
(\%)^{\S}\end{array}$ & $629(54.1)$ & $1891(54.2)$ \\
\hline \multirow{2}{*}{\multicolumn{3}{|c|}{$\begin{array}{l}\text { Usual care includes all participants initially randomized to arm } 1 \text { and received no } \\
\text { interventions throughout the study } \\
\text { Intervention includes all participants initially randomized to arms 2, 3, or } 4 \text { in year } 1 \text {, and } \\
\text { the subgroups randomized to stopped or continued interventions in year } 3\end{array}$}} \\
\hline & & \\
\hline \multicolumn{3}{|c|}{$\begin{array}{l}{ }^{\S} \text { Censored for disenrollment, death, aged greater than } 76, \text { opted out of } \\
\text { participation, CRC diagnosis } \\
\text { CRC colorectal cancer sd standard deviation }\end{array}$} \\
\hline
\end{tabular}


general health, marital status, education, and prior CRC screening history at baseline (Table 1).

On average, the percent covered time was greater among intervention participants $(69.1 \%, 95 \%$ confidence interval [CI] 68.170.1) compared to UC $(57.5 \%, 95 \%$ CI 55.6-59.5\%; adjusted incidence rate ratio [IRR] $1.21,95 \%$ CI $1.16-1.25, P<0.001$ ) (Table 2). Intervention participants were also significantly more likely to have completed at least one CRC test compared to UC ( $88.6 \%$ vs. $80.6 \%, P<0.001)$ over 9 years or until censoring.

Almost all additional coverage was due to increased fecal testing, with the intervention group completing significantly more fecal tests every year except year 4 when no interventions were offered (Table 3). Cumulative covered time increased in both groups over time (Fig. 2). Differences between groups were greatest in years 1 and 2 when everyone in the study intervention groups received mailed only or mailed plus stepped interventions. While the difference between groups became smaller over time, intervention group cumulative percent covered time remained higher than UC (Fig. 2).

Intervention effects on covered time did not differ significantly by patient characteristics. Of the nonsignificant increases in intervention effects on covered time, the largest arose among the combined non-White or Hispanic group compared to White (non-White or Hispanic IRR 1.31 vs. non-Hispanic White, IRR 1.19; $P=0.07$ ) (Supplementary Table 1). Little variation appeared among any subgroups for proportion of individuals ever receiving any screening during follow-up (Supplementary Table 2).

Follow-up diagnostic colonoscopy within 6 months of a positive fecal test was not significantly different between UC and intervention groups $(77.8 \%$ and $73.6 \%$, respectively, data not shown). The percent of patients with metastatic CRC or CRC death, early stage CRC, and advanced adenomas was similar between groups (Supplementary Table 3).

Hospitalizations and deaths within 30 days of a colonoscopy were tracked in years 1 and 2 of the study, and deaths years 1 through 9 , with no hospitalization or deaths related to study interventions.

Table 2 Cumulative Covered Time and Percent with No Screening by Randomization Group. Covered Time Was Measured from Randomization Until the End of 9 Years of Study Follow-up or Censoring at Disenrollment, Death, Aged Greater Than 76, CRC Diagnosis, or Opting Out of Participation. Adjusted for Baseline Age, Sex, Race, and Education

\begin{tabular}{|c|c|c|c|c|}
\hline & $\begin{array}{l}\text { Usual } \\
\text { Care } \\
\mathrm{N}=1163\end{array}$ & $\begin{array}{l}\text { Intervention } \\
\mathbf{N}=\mathbf{3 4 9 0}\end{array}$ & $\begin{array}{l}\text { Intervention } \\
\text { vs. usual care }\end{array}$ & $P$ \\
\hline & $\begin{array}{l}\%(95 \% \\
\text { CI) }\end{array}$ & $\%(95 \%$ CI $)$ & $\begin{array}{l}\text { IRR }(95 \% \\
\text { CI) }\end{array}$ & \\
\hline $\begin{array}{l}\text { Covered } \\
\text { time }\end{array}$ & $\begin{array}{l}57.5 \\
(55.6, \\
59.5)\end{array}$ & $\begin{array}{l}69.1(68.1, \\
70.1)\end{array}$ & $\begin{array}{l}1.21(1.16, \\
1.25)\end{array}$ & $<0.001$ \\
\hline $\begin{array}{l}\text { Receiving } \\
\text { any } \\
\text { screening }\end{array}$ & $\begin{array}{l}80.6 \\
(78.5, \\
82.8)\end{array}$ & $\begin{array}{l}88.6(87.3, \\
89.9)\end{array}$ & $\begin{array}{l}1.11(1.07, \\
1.14)\end{array}$ & $<0.001$ \\
\hline
\end{tabular}

IRR incidence rate ratio, CI confidence interval
Table 3 Types of Testing By Year Among Participants Eligible for CRC Screening. If a Participant Had a Combination of Fecal Tests, Flexible Sigmoidoscopy, or Colonoscopy, Fecal Test Was Counted Only If It Is The First Test. Sigmoidoscopy and Colonoscopy Were Always Counted. Therefore, the Total Number Tested May Be Less Than the Sum of Fecal Test + Flex Sig/Colonoscopy Rows, Due to Those Who Received Fecal Then Endoscopic Testing

\begin{tabular}{|c|c|c|c|}
\hline & \multirow{2}{*}{$\begin{array}{l}\begin{array}{l}\text { Usual } \\
\text { Care }\end{array} \\
\mathrm{N}=1163\end{array}$} & \multirow{2}{*}{$\begin{array}{l}\text { Intervention } \\
\mathrm{N}=\mathbf{3 4 9 0}\end{array}$} & \multirow[t]{2}{*}{$\begin{array}{l}P \text { - } \\
\text { value }\end{array}$} \\
\hline & & & \\
\hline \multicolumn{4}{|l|}{ Year 1} \\
\hline Eligible for screening ${ }^{\dagger}, \mathrm{N}$ & 1163 & 3490 & \\
\hline Fecal test, n $(\%)$ & $299(25.7)$ & $2110(60.5)$ & $<0.001$ \\
\hline $\begin{array}{l}\text { Flex sig/colonoscopy }{ }^{\S}, \mathrm{n} \\
(\%)\end{array}$ & $227(19.5)$ & $650(18.6)$ & 0.55 \\
\hline \multicolumn{4}{|l|}{ Year 2} \\
\hline Eligible for screening ${ }^{\dagger}, \mathrm{N}$ & 870 & 2636 & \\
\hline Fecal test, n (\%) & $177(20.3)$ & $1389(52.7)$ & $<0.001$ \\
\hline $\begin{array}{l}\text { Flex sig/colonoscopy }{ }^{\S}, \mathrm{n} \\
(\%)\end{array}$ & $116(13.3)$ & $307(11.7)$ & 0.21 \\
\hline \multicolumn{4}{|l|}{ Year 3} \\
\hline Eligible for screening ${ }^{\dagger}, \mathrm{N}$ & 712 & 2171 & \\
\hline Fecal test, n $(\%)$ & $193(27.1)$ & $830(38.2)$ & $<0.001$ \\
\hline $\begin{array}{l}\text { Flex sig/colonoscopy }{ }^{\S}, \mathrm{n} \\
(\%)\end{array}$ & $60(8.4)$ & $172(7.9)$ & 0.60 \\
\hline \multicolumn{4}{|l|}{ Year 4} \\
\hline Eligible for screening $^{\dagger}, \mathrm{N}$ & 591 & 1819 & \\
\hline Fecal test, n (\%) & 199 (33.7) & $694(38.2)$ & 0.13 \\
\hline $\begin{array}{l}\text { Flex sig/colonoscopy }{ }^{\S}, \mathrm{n} \\
(\%)\end{array}$ & $44(7.5)$ & $135(7.4)$ & 0.77 \\
\hline \multicolumn{4}{|l|}{ Year 5} \\
\hline Eligible for screening ${ }^{\dagger}, \mathrm{N}$ & 500 & 1583 & \\
\hline Fecal test, $\mathrm{n}(\%)$ & $230(46.0)$ & $874(55.2)$ & $<0.001$ \\
\hline $\begin{array}{l}\text { Flex Sig/Colonoscopy }{ }^{\S} \text {, } \\
\mathrm{n}(\%)\end{array}$ & $27(5.4)$ & $95(6.0)$ & 0.64 \\
\hline \multicolumn{4}{|l|}{ Year 6} \\
\hline Eligible for screening ${ }^{\dagger}, \mathrm{N}$ & 431 & 1339 & \\
\hline Fecal test, n (\%) & $194(45.0)$ & $831(62.1)$ & $<0.001$ \\
\hline $\begin{array}{l}\text { Flex sig/colonoscopy }{ }^{\S}, \mathrm{n} \\
(\%)\end{array}$ & $13(3.0)$ & $64(4.8)$ & 0.13 \\
\hline \multicolumn{4}{|l|}{ Year 7} \\
\hline Eligible for screening $^{\dagger}, \mathrm{N}$ & 395 & 1228 & \\
\hline Fecal test, $\mathrm{n}(\%)$ & $208(52.7)$ & $808(65.8)$ & $<0.001$ \\
\hline $\begin{array}{l}\text { Flex sig/colonoscopy }{ }^{\S}, \mathrm{n} \\
(\%)\end{array}$ & $7(1.8)$ & $68(5.5)$ & 0.005 \\
\hline \multicolumn{4}{|l|}{ Year 8} \\
\hline Eligible for screening ${ }^{\dagger}, \mathrm{N}$ & 350 & 1039 & \\
\hline Fecal test, n $(\%)$ & $203(58.0)$ & $690(66.4)$ & 0.004 \\
\hline $\begin{array}{l}\text { Flex sig/colonoscopy }{ }^{\S}, \mathrm{n} \\
(\%)\end{array}$ & $11(3.1)$ & $55(5.3)$ & 0.09 \\
\hline \multicolumn{4}{|l|}{ Year 9} \\
\hline Eligible for screening ${ }^{\dagger}, \mathrm{N}$ & 303 & 873 & \\
\hline Fecal test, $\mathrm{n}(\%)$ & $168(55.5)$ & $583(66.8)$ & 0.001 \\
\hline $\begin{array}{l}\text { Flex sig/colonoscopy }{ }^{\S}, \mathrm{n} \\
(\%)\end{array}$ & $10(3.3)$ & $33(3.8)$ & 0.39 \\
\hline
\end{tabular}

Eligible for screening in a year if had not received a flexible sigmoidoscopy or colonoscopy, a positive fecal test, or been censored (diagnosis of CRC, died, reached age 76, or disenrolled from the health plan) in a prior year

P-values from separate Poisson models for each year and type of test, with follow-up time as offset parameter, adjusted for age, sex, race, and education. Models limited to individuals eligible for screening in a given year

${ }^{\S}$ Colonoscopy accounted for most testing reported in the "Flex sig/ colonoscopy" rows. The number of flexible sigmoidoscopies were as follows: year $1 U C=52$, intervention $=169$; year $2 U C=7$, intervention $=24$; year $3 U C=0$, intervention $=7$; year $4 U C=2$, intervention $=4$; year $5 U C=0$, intervention $=5$; year $6 U C=0$, intervention $=1$; years $7-9$ $U C=0$, intervention $=0 . \quad C R C$ colorectal cancer, flex sig flexible sigmoidoscopy

\section{DISCUSSION}

We demonstrated that an ongoing centralized mailed intervention resulted in more than $20 \%$ higher of time adherent to CRC 


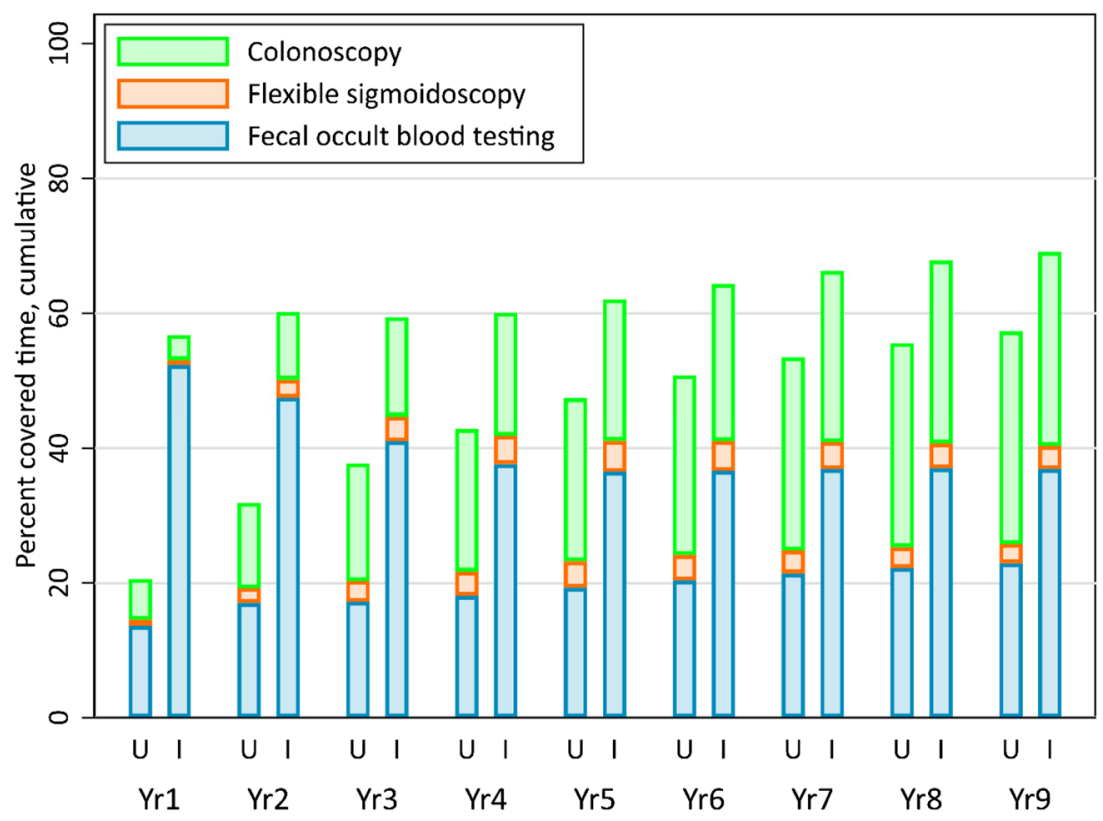

Figure 2 Cumulative percent covered time by colorectal cancer test type in the usual care and intervention arms. In this figure, the cumulative percent covered time for a given year is defined as the number of days of covered time from baseline through the end of that year, divided by the total follow-up time for that person, from baseline through the end of that year or censor date.

screening guidelines compared to UC over 9 years. Further, the interventions increased the percent of patients receiving CRC testing by almost $8 \%$.

Differences between groups in adherence were due almost entirely to increased uptake in fecal testing. Screening adherence defined as the cumulative proportion of time covered increased steadily in the UC-only group, particularly after KPWA switched from guaiac to FIT screening. However, screening adherence in the UC-only group (which included clinic-based interventions to increase CRC screening) never caught up to the intervention group, resulting in lower adherence over the 9 years of follow-up.

Our study is the first randomized controlled implementation CRC screening trial we know of with 9 years of follow-up. Prior studies looked at adherence over shorter times. Singal et al., in a safety-net integrated health system, randomized 5999 individuals aged 50-64 to receive mailed FITs annually over 3 years, colonoscopy outreach, or UC with clinic-based screening. ${ }^{11}$ Screening adherence, defined as completion of colonoscopy or FIT annually over 3 years, was significantly greater in the colonoscopy outreach $(38.4 \%)$ and the mailed FIT arms (28.0\%) than UC (10.7\%). Time in adherence was not accounted for, with full credit given for completing a colonoscopy regardless of time without screening, and no credit given to individuals completing one or two annual FITs.

Liang et al., in a community safety-net setting, randomized 997 individuals aged 50-70 to receive guaiac fecal tests annually over 3 years, colonoscopy, or a choice between FIT and colonoscopy. ${ }^{12}$ All groups were offered patient navigation in year 1, with assistance in completing fecal or colonoscopy testing. Screening adherence was defined as completion of colonoscopy in year 1 or fecal testing in all 3 years and was significantly higher in colonoscopy (38\%) and choice (42\%) groups, compared to fecal testing (14\%). A potential advantage of colonoscopy is the 10 years of average-risk screening coverage, whereas fecal testing needs to be repeated annually. SOS participants were offered choices but increases in longterm adherence were mainly from repeated completion of fecal testing.

To our knowledge, prior CRC screening trials have not looked at proportion of time covered. This measure is valuable because it gives a more complete picture of longitudinal adherence as it reflects delays and gaps in screening. ${ }^{29,30}$ Our intervention improved longitudinal adherence, measured as proportion of time covered overall, and among individuals identifying their race/ethnicity other than White. Similar to SOS, Mehta et al., in an evaluation of a large US CRC mailed FIT screening program, found that all racial/ethnic groups had marked increases in CRC screening rates as a result of the program. ${ }^{32}$

We previously demonstrated in SOS that, compared to UC, mailed-only interventions led to large increases in screening adherence over the first 2 years $(24.5 \%, 95 \%$ CI 20.6-28.4), with smaller incremental increases for mailed plus phone assistance compared to mailed-only interventions $(6.7 \%, 95 \%$ CI $2.7,10.7)$, and nurse navigation compared to mailed plus assistance $(7.2,95 \% \mathrm{CI}$ $3.4,11.0) .{ }^{6}$ Mailed-only intervention was cost saving and nurse navigation was low cost per additional person screened. ${ }^{25}$ Even though our stepped approach ensured that only those with most need (e.g., not responding to mailings) received nurse navigation, health systems and community clinics may be challenged in finding these resources. $^{33}$ 
We also demonstrated in two separate studies that mailed fecal testing programs can be successfully implemented in Federally Qualified Health Centers and by Medicaid health plans, and were effective across groups by ethnicity, income, and insurance type (including uninsured). ${ }^{34,35}$ Successful strategies included use of mail vendors and non-clinic or quality improvement staff who had protected time to implement the program. ${ }^{36}$

Ultimately, the goal of a CRC screening program is to reduce $\mathrm{CRC}$ mortality. Large-scale randomized controlled efficacy trials ${ }^{37,38}$ and organized US and international mailed fecal testing programs have showed declines in CRC mortality. ${ }^{39-42}$ These programs and our study provide evidence of the benefits of organized CRC screening programs. However, organized, ongoing CRC screening outreach is uncommon in the USA, where most CRC screening is opportunistic. US health systems are not reimbursed for implementing screening programs, and long-term savings from reduction of CRC treatment costs are not recouped short-term. ${ }^{33}$

The COVID-19 pandemic has dramatically highlighted the need for broader implementation of mailed fecal testing programs. Organizations such as the US Department of Veterans Affairs suspended all screening colonoscopies, but continued FIT screening, reserving colonoscopies for individuals with positive tests who are more likely to have CRC. ${ }^{43}$ COVID-19related screening delays may lead to a surge in late-stage CRC and CRC death. ${ }^{44-46}$ Mailed FIT programs could mitigate this risk. $^{47}$

Study strengths include the pragmatic design, with the program integrated into care delivery and outcomes collected annually and over 9 years using EHR and claims data. Limitations were that participants provided verbal consent in year 1 , and therefore were "volunteers" potentially more responsive to interventions. ${ }^{23}$ Also, patients had health insurance, were mostly White and non-Hispanic, and had higher education levels than the US population. Thus, our findings may be less generalizable to other populations. Our outcome included CRC tests regardless of indication (i.e., screening or diagnostic) and some tests categorized as screening might have been completed because of symptoms. ${ }^{48}$ However, since we would not expect major differences in diagnostic testing across groups, we attribute the observed differences between groups to screening. Lastly, our study was complex. Our initial study tested adherence to screening over 2 years and intervention participants were re-randomized to stopped or continued mailed interventions in years 3 and 5, this plus nurse navigation in years 6-9. By combining the stopped and continued groups for comparison to UC only, our estimates for potential achievements of an ongoing outreach program are conservative.

In conclusion, our study is the first randomized controlled trial to demonstrate that a centralized mailed screening program increases adherence to guideline-recommended CRC screening over 9 years. The centralized program also significantly decreased the proportion of eligible individuals with no
CRC testing over 9 years. Our study provides additional confirmation to a substantial body of evidence that underscores the need for organized CRC screening programs to be a standard of care throughout the USA and worldwide.

Acknowledgements: We acknowledge the contributions of Kris Hansen MS, project manager; Christine Mahoney MA, project manager, Killian Kimbel BA, research assistant; Leslie Jauregui, research assistant; Chris Tachibana PhD, scientific editor.

Supplementary Information The online version contains supplementary material available at https://doi.org/10.1007/s11606-02106922-2.

Corresponding Author: Beverly B. Green, MD, MPH; Kaiser Permanente Washington Health Research Institute, Seattle, WA, USA (e-mail: Bev.B.Green@kp.org).

Author Contribution Study design: Green, Anderson, Chubak, Cook, Meenan, Vernon

Acquisition of data: Fuller, Chubak

Analysis: Anderson, Cook

Interpretation of data: all authors

Drafting of the manuscript: Green, Anderson

Revising: all authors

Dr. Green is the corresponding author

Dr. Green and Ms. Anderson take full accountability for all aspects of the work. All authors have approved the submission of this manuscript.

Funding Study data presented here were collected from August 2008 to November 2018 and were supported by a grant from the National Cancer Institute at the National Institutes of Health (RO1CA121125).

Data Availability Deidentified datasets and a data dictionary of the data presented in this manuscript are available upon request to the corresponding author.

\section{Declarations:}

Disclaimer: This study is the sole responsibility of the authors and does not necessarily represent the official view of the National Cancer Institute or National Institutes of Health.

\section{REFERENCES}

1. Siegel RL, Miller KD, Goding Sauer A, et al. Colorectal cancer statistics, 2020. CA Cancer J Clin. 2020;70(3):145-164.

2. American Cancer Society. Cancer facts \& figures 2021. 2021; https:// www.cancer.org/research/cancer-facts-statistics/all-cancer-facts-figures/cancer-facts-figures-2021.html. Accessed April 14, 2021.

3. Freedman JD, Mitchell CK. A simple strategy to improve patient adherence to outpatient fecal occult blood testing. $J$ Gen Intern Med. 1994;9(8):462-464.

4. Church TR, Yeazel MW, Jones RM, et al. A randomized trial of direct mailing of fecal occult blood tests to increase colorectal cancer screening. J Natl Cancer Inst. 2004;96(10):770-780.

5. Coronado GD, Golovaty I, Longton G, Levy L, Jimenez R. Effectiveness of a clinic-based colorectal cancer screening promotion program for underserved Hispanics. Cancer. 2011;117(8):1745-1754.

6. Green BB, Wang CY, Anderson ML, et al. An automated intervention with stepped increases in support to increase uptake of colorectal cancer screening: a randomized trial. Ann Intern Med. 2013;158(5 Pt 1):301-311.

7. Gupta S, Halm EA, Rockey DC, et al. Comparative effectiveness of fecal immunochemical test outreach, colonoscopy outreach, and usual care for boosting colorectal cancer screening among the underserved: a randomized clinical trial. JAMA Intern Med. 2013;173(18):1725-1732. 
8. Baker DW, Brown T, Buchanan DR, et al. Comparative effectiveness of a multifaceted intervention to improve adherence to annual colorectal cancer screening in community health centers: a randomized clinical trial. JAMA Intern Med. 2014;174(8):1235-1241.

9. Dougherty MK, Brenner AT, Crockett SD, et al. Evaluation of interventions intended to increase colorectal cancer screening rates in the United States: a systematic review and meta-analysis. JAMA Intern Med. 2018;178(12):1645-1658.

10. Jager M, Demb J, Asghar A, et al. Mailed outreach is superior to usual care alone for colorectal cancer screening in the USA: A systematic review and meta-analysis. Dig Dis Sci. 2019;64(9):2489-2496.

11. Singal AG, Gupta S, Skinner CS, et al. Effect of colonoscopy outreach vs fecal immunochemical test outreach on colorectal cancer screening completion. JAMA. 2017;318(9):806-815.

12. Liang PS, Wheat $\mathbf{C L}$, Abhat $\mathbf{A}$, et al. Adherence to competing strategies for colorectal cancer screening over 3 years. Am $J$ Gastroenterol. 2016;111(1):105-114.

13. Murphy CC, Sen A, Watson B, Gupta S, Mayo H, Singal AG. A systematic review of repeat fecal occult blood tests for colorectal cancer screening. Cancer Epidemiol Biomarkers Prev. 2020;29(2):278-287.

14. Kapidzic A, Grobbee EJ, Hol L, et al. Attendance and yield over three rounds of population-based fecal immunochemical test screening. Am J Gastroenterol. 2014;109(8):1257-1264.

15. Levin TR, Jamieson L, Burley DA, Reyes J, Oehrli M, Caldwell C. Organized colorectal cancer screening in integrated health care systems. Epidemiol Rev. 2011;33(1):101-110.

16. Steele RJ, McClements PL, Libby G, Carey FA, Fraser CG. Patterns of update in a biennial faecal occult blood test screening programme for colorectal cancer. Colorectal Dis. 2014;16(1):28-32.

17. van der Vlugt M, Grobbee EJ, Bossuyt PM, et al. Adherence to colorectal cancer screening: four rounds of faecal immunochemical testbased screening. Br J Cancer. 2017;116(1):44-49.

18. Murphy CC, Sigel BM, Yang E, et al. Adherence to colorectal cancer screening measured as the proportion of time covered. Gastrointest Endosc. 2018;88(2):323-331. e322.

19. Gellad ZF, Stechuchak KM, Fisher DA, et al. Longitudinal adherence to fecal occult blood testing impacts colorectal cancer screening quality. Am $J$ Gastroenterol. 2011;106(6): 1125-1134.

20. Jensen CD, Corley DA, Quinn VP, et al. Fecal immunochemical test program performance over 4 rounds of annual screening: a retrospective cohort study. Ann Intern Med. 2016;164(7):456-463.

21. Systems of Support (SOS) to increase colon cancer screening and followup. 2008; https://www.clinicaltrials.gov/ct2/show/NCT00697047. Accessed April 14, 2021.

22. Green BB, Wang CY, Horner $\mathbf{K}$, et al. Systems of support to increase colorectal cancer screening and follow-up rates (SOS): design, challenges, and baseline characteristics of trial participants. Contemp Clin Trials. 2010;31(6):589-603.

23. Green BB, Bogart A, Chubak $\mathbf{J}$, et al. Nonparticipation in a populationbased trial to increase colorectal cancer screening. Am J Prev Med. 2012;42(4):390-397.

24. Green BB, Anderson ML, Chubak J, et al. Colorectal cancer screening rates increased after exposure to the Patient-Centered Medical Home (PCMH). J Am Board Fam Med. 2016;29(2):191-200.

25. Meenan RT, Anderson ML, Chubak J, et al. An economic evaluation of colorectal cancer screening in primary care practice. Am J Prev Med. 2015;48(6):714-721.

26. Green BB, Anderson ML, Chubak J, Fuller S, Meenan RT, Vernon Sw. Impact of continued mailed fecal tests in the patient-centered medical home: Year 3 of the Systems of Support to Increase Colon Cancer Screening and Follow-Up randomized trial. Cancer. 2016;122(2):312-321.

27. Green BB, Anderson ML, Cook AJ, et al. A centralized mailed program with stepped increases of support increases time in compliance with colorectal cancer screening guidelines over 5 years: A randomized trial. Cancer. 2017;123(22):4472-4480.

28. Green BB, BlueSpruce J, Tuzzio L, Vernon SW, Aubree Shay L, Catz SL. Reasons for never and intermittent completion of colorectal cancer screening after receiving multiple rounds of mailed fecal tests. BMC Public
Health. 2017;17(1):531.

29. Murphy CC, Halm EA, Skinner CS, Balasubramanian BA, Singal AG. Challenges and approaches to measuring repeat fecal immunochemical test for colorectal cancer screening. Cancer Epidemiol Biomarkers Prev. 2020;29(8): 1557-1563

30. Chubak J, Anderson ML, Cook AJ, Murphy CC, Jackson ML, Green BB. Methodologic considerations in calculating and analyzing proportion of time covered as a measure of longitudinal cancer screening adherence. Cancer Epidemiol Biomarkers Prev. 2020;29(8):1549-1556.

31. National Cancer Institute. SEER Registries. https://seer.cancer.gov/ registries/. Accessed April 14, 2021.

32. Mehta SJ, Jensen CD, Quinn VP, et al. Race/ethnicity and adoption of a population health management approach to colorectal cancer screening in a community-based healthcare system. $J$ Gen Intern Med. 2016;31(11):1323-1330.

33. Green BB, Meenan RT. Colorectal cancer screening: The costs and benefits of getting to $80 \%$ in every community. Cancer. 2020;126(18):4110-4113.

34. Coronado GD, Petrik AF, Vollmer WM, et al. Effectiveness of a mailed colorectal cancer screening outreach program in community health clinics: The STOP CRC Cluster Randomized Clinical Trial. JAMA Intern Med. 2018;178(9):1174-1181.

35. Coronado GD, Green BB, West, II, et al. Direct-to-member mailed colorectal cancer screening outreach for Medicaid and Medicare enrollees: Implementation and effectiveness outcomes from the BeneFIT study. Cancer. 2020;126(3):540-548.

36. Petrik AF, Green B, Schneider J, et al. Factors influencing implementation of a colorectal cancer screening improvement program in community health centers: an applied use of configurational comparative methods. J Gen Intern Med. 2020;35(Suppl 2):815-822.

37. Shaukat A, Mongin SJ, Geisser MS, et al. Long-term mortality after screening for colorectal cancer. $N$ Engl J Med. 2013;369(12):1106-1114.

38. Kronborg O, Jørgensen O, Fenger C, Rasmussen M. Randomized study of biennial screening with a faecal occult blood test: results after nine screening rounds. Scand J Gastroenterol. 2004;39(9):846-851.

39. Levin TR, Corley DA, Jensen CD, et al. Effects of organized colorectal cancer screening on cancer incidence and mortality in a large community-based population. Gastroenterology. 2018;155(5): 1383-1391 e1385.

40. Chiu HM, Chen SL, Yen AM, et al. Effectiveness of fecal immunochemical testing in reducing colorectal cancer mortality from the One Million Taiwanese Screening Program. Cancer. 2015;121(18):3221-3229.

41. Hamza S, Cottet V, Touillon N, et al. Long-term effect of faecal occult blood screening on incidence and mortality from colorectal cancer. Dig Liver Dis. 2014;46(12):1121-1125.

42. Gini A, Jansen EE, Zielonke N, et al. Impact of colorectal cancer screening on cancer-specific mortality in Europe: A systematic review. Eur $J$ Cancer. 2020;127:224-235.

43. Gawron AJ, Kaltenbach T, Dominitz JA. The impact of the coronavirus disease-19 pandemic on access to endoscopy procedures in the VA healthcare system. Gastroenterology. 2020;159(4):1216-1220 e1211.

44. Maringe C, Spicer J, Morris M, et al. The impact of the COVID-19 pandemic on cancer deaths due to delays in diagnosis in England, UK: a national, population-based, modelling study. Lancet Oncol. 2020;21(8): 1023-1034.

45. Aguiar S, Riechelmann RP, de Mello CAL, et al. Impact of COVID-19 on colorectal cancer presentation. Br J Surg. 2021;108(2):e81-e82.

46. Rutter MD, Brookes M, Lee TJ, Rogers P, Sharp L. Impact of the COVID-19 pandemic on UK endoscopic activity and cancer detection: a National Endoscopy Database Analysis. Gut. 2021;70(3):537-543.

47. Nodora JN, Gupta S, Howard N, et al. The COVID-19 pandemic: Identifying adaptive solutions for colorectal cancer screening in underserved communities. J Natl Cancer Inst. 2020.

48. Chubak J, Hubbard R. Defining and measuring adherence to cancer screening. J Med Screen. 2016;23(4):179-185.

Publisher's Note: Springer Nature remains neutral with regard to jurisdictional claims in published maps and institutional affiliations. 